\title{
Investigating occupational stress of disaster and investigating occupational stress of disaster and emergency medical management center 115 and the role of demographic variables
}

Javad Yoosefi lebni

Tehran University of Medical Sciences

Parvin Abdi Gheshlaghi

Kermanshah University of Medical Sciences

Razie Toghroli

Hormozgan University of Medical Sciences

Vahid Hatami Garosi

Kermanshah University of Medical Sciences

Jaffar Abbas

Shanghai Jiao Tong University

Reza Pourmirza Kalhori

Kermanshah University of Medical Sciences

Mohammad Reza Salahshoor

Kermanshah University of Medical Sciences

Neda Kianipour

Kermanshah University of Medical Sciences

Munira Tharwani

Cyberjaya University College of Medical Sciences

arash ziapour ( $\square$ arashziapoor@gmail.com )

Kermanshah University of Medical Sciences https://orcid.org/0000-0001-8687-7484

Research article

Keywords: Occupational stress, Emergency medical, Emergency department, Demographic variables, Kermanshah, Iran

Posted Date: July 31st, 2020

DOI: https://doi.org/10.21203/rs.3.rs-32075/v2 
License: (c) (i) This work is licensed under a Creative Commons Attribution 4.0 International License. Read Full License 


\section{Abstract}

Background: The first and one of the most important chains of providing care to patients is pre-hospital emergency medical services. Personnel employed in this sector are at risk of occupational stress due to the nature of their job which can affect their health and quality of services provided to patients. Therefore, the present study was conducted to investigate the occupational stress of the personnel of disaster and emergency medical management center 115 and the role of demographic variables in 2019.

Methods: This is a descriptive-analytical study. 200 medical emergency personnel of Kermanshah province were selected through stratified sampling and according to inclusion criteria. A two-part questionnaire including demographic information and HSE standard questionnaire were used for collecting data. Finally, descriptive and inferential statistics (t-test and one-way ANOVA) were used for data analysis. Significance level was considered $\mathrm{P}<0.05$.

Results: The mean score of total occupational stress was $3.41 \pm 0.26$. The highest and the lowest stress levels related to the role dimensions was calculated $(4.34 \pm 0.35)$ and changes $(2.72 \pm 0.86)$. There was a significant relationship between stress level with age, marital status, educational level, type of base of work place and hours of work per month, while there was no relationship between type of employment and work experience with stress level.

Conclusion: Emergency medical personnel experience a high level of occupational stress. Senior managers can use the results of similar studies to think measures to reduce the experience of employees' stress.

\section{Background}

Disasters are one of the most challenging problems and are a threat to the health of communities in the world. They comprise of $12 \%$ of the global burden of diseases and it is the third most common cause of death [1]. Stress is an inevitable and essential part of life and follows a pervasive phenomenon. General human being experiences stress, which is essential for its survival and growth. It affects every individual regardless of age, gender, race, economic status or education level. Although it is a natural and necessary aspect of life, if the stress is severe, persistent, or repetitive, the individual maybe is unable to cope effectively with it. In the event where support resources are scarce and casualties are increasing, stress is considered as a negative phenomenon or catastrophe, which may cause physical and mental disorders [2]. One of the most important sources of stress in any person's life is his/her job; hence, occupational stress has become a common and neglected issue in the workplace. It has negative consequences and an overall high cost to bear. As a result, so the United Nations has called it a twentieth-century disease. In recent years, the World Health Organization (WHO) has declared it a widespread problem [3]. Occupational stress is a type of emotional, cognitive, behavioral, and psychological response to harmful aspects of work and the work environment [4]. In general, occupational stress is a result of stress caused 
by work environment and it is occurred when expectations are higher than employees' abilities and authorities [5].

Numerous studies have shown the role of occupational stress in connection with disease symptoms, high labor displacement, and early retirement of individuals [6]. The Health and Safety Executive has predicted over 13.5 million working days and more than $£ 4$ billion losses annually due to the damages from occupational stresses during 2007-2009[7]. Occupational stress is a situation that results from the interaction between individuals and jobs, including changes occurring within individuals that force them to deviate from their normal way of action [8].

In this regard, several organizations have been founded to protect the health and well-being of people., One of these organizations is the Disaster and Emergency Medical Management Center, which is responsible for providing clinical care to patients in pre-hospital medical emergency and transferring to medical centers if necessary [9]. The center is considered one of the main pillars of health care in all countries of the world and the most important goal of this system is to provide satisfactory services in the shortest possible time and in accordance with the modern scientific standards of the world [10]. Emergency medical services units differ from the other sections through variety of ways, such as stressful environments, high pressure, sensitivity of seconds, extraordinary stress on timely diagnosis, expectations and pressure of near and dear ones and the importance of protecting patients' lives [11]. Therefore, this is the highly stressed area of the medical services unit. The emergency medical services system is a part of a chain system responsible for the care of patients from the severe critical time to their rehabilitation and discharge. [12]. The personnel employed in this section are as the first individuals to respond to patients in emergency medical situations and the first sight of the critical moment[13]. This section provides the conditions in creating stress for the personnel employed in this sector due to time constraints in performing affairs, critical status of patient, expectations of companions, openness of the environment, fear of inadequacy in rescuing a dying patient, decision-making power in critical situations and factors related to manpower [14]. In other words, the physical, mental, and intellectual stressors cause the emergency medical technicians to be exposed at high risk, such as accidents, errors, and other injuries to persons (6). The clear examples of symptoms of occupational stress include insomnia, distraction, anxiety, absenteeism, depression, fatigue, excessive frustration, family problems, and physical problems such as heart disease, migraines, headaches, indigestion, and disc herniation between the lumbar vertebrae [15]. Increasing working hours causes the increase of conflict in occupational and family tasks which can lead to occupational stress [15]. The rotating nature of work shifts of emergency medical technicians gives little opportunity to adapt to sleep patterns that can lead to the disruption in mental health [16]. So that the effects of day and night shifts can be fatigue, sleep disorder, gastrointestinal disorders and poor performance [17].

In domestic studies, Sharifi et al. in their study in Kerman concluded that about half of emergency medical personnel experienced moderate occupational stress. There was a significant relationship between occupational stress with educational level and employment status, while age and marital status didn't have any relationship with stress [18]. The results of Dadashzadeh et al. study in urban and road 
bases and pre-hospital emergency medical services in East Azarbaijan province showed that the most important factor of stress load is occupational environmental factors and factors related to patient. There was also a significant relationship between the amount of stress load with the number of missions, educational degree, and type of base and employment status [19]. Seyed Javadi et al. in a study conducted on employees in 115 provinces of Ardabil stated that there was a significant correlation between age and occupational stress but there was no relationship between stress and marital status, educational level, type of base of work place and working hours per week [20].

In foreign studies, the results of a study in the UK showed that emergency medical technicians had the highest rank in terms of physical stress, the second rank in terms of dissatisfaction and the fourth rank in terms of mental health comparing to the other 25 jobs [21]. The results of a study in Turkey showed that all the stressful and negative conditions in the pre-hospital emergency medical services lead to physical and psychological fatigue of the personnel and eventually lead to the development of burnout [22]. Leszczynski et al. stressed that physicians and nurses in the emergency medical services department suffered more burnout compared to emergency medical personnel. They stated that emergency medical service personnel experienced the least amount of burnout compared to their colleagues [23]. Yuwanich et al. in Thailand announced that nurses of emergency medical services department are more at risk of occupational stress compared to nurses in other departments and less work experience is related to the stress [15].

In spite of all the studies conducted, reviewing different backgrounds indicates that no study has been conducted in Kermanshah University of Medical Sciences to assess the occupational stress of the personnel employed in 115 of Kermanshah provinces. Keeping in view the stature of job, occupational stress is prominent in people working for emergency medical which is considered as a key element in health systems, because it provides the optimal provision of health care and clinical services for affected at critical moment. This study was conducted to investigate the occupational stress status of the personnel of the disaster and emergency medical management center 115 and the role of demographic variables play in 2019. This issue enables planning and comparison with other areas of the country while identifying specific cases that need support, counseling and treatment.

\section{Method}

\section{Study design}

This cross-sectional descriptive-analytical study was conducted from May to September of 2019. 200 male technicians employed in Emergency Medical Centers affiliated to Kermanshah University of Medical Sciences were selected using calculation formula of Cochran sample size (95\% confidence level and 5\% error) by stratified random sampling method appropriate with the population size. In this study 85 urban base personnel and 115 personnel of emergency medical road bases of 115 entered the study. 
The ethical principle in conducting this study was met by approving the project at the respectful research council of Kermanshah University of Medical Sciences and taking a sampling license. Researchers based on the personnel list, individuals and road specified the study criteria. The research project was approved by the Research Ethics Committee of Kermanshah University of Medical Sciences and informed consent was obtained from all study units. In order to prevent fatigue of the samples, respondents were asked to fill the questionnaires at home. The time required to complete each questionnaire was 15-20 minutes and data was collected within 9 weeks. Inclusion criteria was: 1-Being employed in pre-hospital emergency medical ambulance as one of the technical categories (rescuer, basic, middle and senior technician) (technicians employed in office and communication center were not considered. 2- The main job of the technician is to work in an ambulance 115 (not as overtime from other units and employment in low volume) 3- having work experience of more than six months in an emergency medical services 115 with a diploma degree and above. Unwillingness to participate in the study and incomplete completion of the questionnaires were considered as exclusion criteria. All research samples were explained that participation in this study was optional and all information is without name and will be kept confidential.

The questionnaire was given to 8 faculty members of nursing, psychology and emergency medicine and 6 emergency medical personnel to the face and content validity of the tool has to be determined.

\section{Tools}

Data was collected using a two-part questionnaire. The first part was related to the demographic variables which included: age, marital status, education level, field of education, work experience, employment status, base of workplace (urban, road, both), and also categorized by hours of work per month (under 150 hours, 150 to 200 hours, 200 to 250 hours) and the second part was the standard occupational stress questionnaire related to the British Health and Safety Executive (HSE) [21].

This questionnaire has 35 items with 7 sub-scales for item of demand covering questions related to workload, characteristics and work environment with 8 items (questions 3, 6, 9, 12, 16, 18, 20 and 22), control specifying questions on how much it can be said that a person is on the path of doing his/her job effectively with 6 items (questions 2, 10, 15, 19, 25 and 30), support of authorities signifies the amount of support that a person receives from their management and service organization categorized with 5 items (questions 8, 23, 29, 33 and 35); support of colleagues measures the amount of support that a person receives from his/her colleagues was allocated with 4 items (questions 7, 24, 27 and 31); relationship characterizes with Increase of practice and positive attribute to increase mass communication and reduce conflict in the workplace have a distribution of 4 items (questions 5, 14, 21 and 34), role attributes to right understanding of personnel from their organization allocates 5 items(Questions 1, 4, 11, 13 and 17) and changes which address How to organize and changes of an organization's forces measure the outcome with 3 items (questions 26, 28 and 32). The questions of this questionnaire include a five-point Likert scale (never, rarely, sometimes, often, and always) that scores from 1 to 5 , respectively. High score from this questionnaire indicate less occupational stress [13]. The occupational stress questionnaire (HSE) was valid and reliable in the study by Azad Marzabadi et al. that its reliability was obtained $78 \%$ 
based on Cronbach's alpha coefficient [24]. Its internal consistency was $89 \%$ based on Cronbach's alpha coefficient.

\section{Data Analysis}

Descriptive (frequency, percentage, mean and standard deviation) and inferential statistics (ANOVA and independent t-test) and SPSS statistical software version 23.0 were employed. The significance level was set at $p<0.05$.

\section{Ethical approval}

Ethical approval was obtained from the Ethical Review Committee of KUMS. The purpose of the study was explained to all participants. Written informed consent was obtained from all participants, and they were assured of anonymity and confidentiality.

\section{Results}

In this study, the sample size consisted of 200 emergency medical personnel in Kermanshah province, which were all male. Therefore, the gender factor was excluded in this study. The results showed that the mean age of participants was 30.14 , with a standard deviation of 5.96 years. More than half of the participants (58\%) were in the age range of $20-30$ years. $57 \%$ of them were married, and the rest were single. Most of individuals ( $80 \%$ ) had an emergency medical degree and almost all of them ( $98 \%)$ had an associate degree (48.5\%) or bachelor's degree (49.5\%). Nearly half of the individuals (47.5\%) had less than 5 years of work experience and $35.5 \%$ were working on the majority of the project. In terms of type of base with respect to the work place, $42.5 \%$ of individuals were in urban base and $57.5 \%$ were in road base. More than half of them (58\%) worked between 200 and 250 hours per month (Table 1).

Mean and standard deviation of total score of occupational stress was $3.41 \pm 0.26$. The highest and the lowest level of occupational stress were related to role dimensions $(4.34 \pm 0.35)$ and changes $(2.72 \pm$ 0.86) (Table 2).

The mean total score of occupational stress in single individuals $(3.48 \pm 0.29)$ was higher than married individuals $(3.35 \pm 0.23)$ and independent $t$-test showed a significant difference $(P=0.001)$. The results of this test showed that the mean total score of occupational stress in individuals employed in urban base $(3.49 \pm 0.24)$ was significantly higher than those employed in road base $(3.34 \pm 0.26)(P=0.000)$ (Table 3). The mean score of stress in terms of demand, control and change showed a significant relationship with the type of base of work place $(P<0.05)$, hence, the mean score in all these dimensions in employees employed in urban bases was more than road bases (Table 4).

The result of ANOVA test showed that the mean total score of occupational stress has been decreased significantly with increasing age $(P=0.000)$. ANOVA test showed a significant relationship between job stress with educational level and field of education $(P=0.000)$, individuals with master's degree had higher occupational stress score $(3.60 \pm 0.07)$ and individuals with emergency medical degree had a 
lower score $(3.37 \pm 0.26)$ compared to other grades and fields. On the other hand, the results of this test showed that there is a significant relationship between occupational stress score and working hours per month $(P=0.000)$; therefore, individuals with the lowest working hours (less than 150 hours per month) had higher occupational stress score $(3.60 \pm 0.23)$. However, there was no significant relationship between work experience $(P=0.092)$ and type of employment $(P=0.241)$ with occupational stress score (Table 3). 
Table 1

Individual characteristics of study samples

\begin{tabular}{|c|c|c|}
\hline \multicolumn{2}{|c|}{ Characteristics of research sample } & \multirow{2}{*}{$\begin{array}{l}\mathbf{N}(\%) \\
86(43 \%)\end{array}$} \\
\hline Married status & Single & \\
\hline & Married & $114(57 \%)$ \\
\hline Age (year) & $30-20$ & $116(58 \%)$ \\
\hline \multirow[t]{2}{*}{$30.14 \pm 5.96$} & $40-31$ & $74(37 \%)$ \\
\hline & $50-41$ & $10(5 \%)$ \\
\hline \multirow[t]{3}{*}{ Education level } & Associate degree & (48.5\%) 97 \\
\hline & Bachelor's degree & (49.5\%) 99 \\
\hline & Master's degree & $(2 \%) 4$ \\
\hline \multirow[t]{4}{*}{ Education degree } & Emergency medical services & $160(80 \%)$ \\
\hline & Nurse & $18(9 \%)$ \\
\hline & Anesthesia & $10(5 \%)$ \\
\hline & Practical nurse & $12(6 \%)$ \\
\hline \multirow[t]{4}{*}{ Work experience } & Less than 5 years & $95(47.5 \%)$ \\
\hline & $10-6$ & $70(35 \%)$ \\
\hline & $20-11$ & $27(13.5 \%)$ \\
\hline & $30-21$ & $8(4 \%)$ \\
\hline \multirow[t]{4}{*}{ Type of employment } & Formal & $39(19.5 \%)$ \\
\hline & contractual & $50(25 \%)$ \\
\hline & Informal & $40(20 \%)$ \\
\hline & Plan & $71(35.5 \%)$ \\
\hline \multirow[t]{2}{*}{ Base of workplace } & Urban & $85(42.5 \%)$ \\
\hline & Road & $115(57.5 \%)$ \\
\hline \multirow[t]{3}{*}{ Work hour per month } & $<150$ & $(13 \%) 26$ \\
\hline & $200-150$ & $(29 \%) 58$ \\
\hline & $250-200$ & $(58 \%) 116$ \\
\hline
\end{tabular}


Table 2

Mean and standard deviation of occupational stress dimensions in the study population Variable

\begin{tabular}{|c|c|c|c|c|c|}
\hline \multicolumn{2}{|l|}{ Statistical indicators } & \multirow[t]{2}{*}{ Mean-SD } & \multirow[t]{2}{*}{ Number (question) } & \multirow[t]{2}{*}{ Min. } & \multirow[t]{2}{*}{ Max } \\
\hline Scale & Sub-scales & & & & \\
\hline \multirow[t]{8}{*}{ Occupational stress } & Demand & $3.71 \pm 0.43$ & 8 & 2.50 & 4.75 \\
\hline & Control & $3.12 \pm 0.60$ & 6 & 2 & 4.33 \\
\hline & Support of authorities & $2.87 \pm 0.68$ & 5 & 1.80 & 4.40 \\
\hline & Support of colleague & $3.46 \pm 0.65$ & 4 & 2 & 4.75 \\
\hline & Relation & $3.61 \pm 0.69$ & 4 & 2 & 5 \\
\hline & Role & $4.34 \pm 0.35$ & 5 & 3.80 & 5 \\
\hline & Changes & $2.72 \pm 0.86$ & 3 & 1.33 & 4.67 \\
\hline & Total occupational stress & $0.26 \pm 3.41$ & 35 & 2.77 & 3.86 \\
\hline Max $=$ Maximum & & & & & \\
\hline
\end{tabular}


Table 3

Comparison of mean and standard deviation of occupational stress score according to demographic variables

\begin{tabular}{|c|c|c|c|}
\hline Variable & Groups & Mean \pm SD & P-Value \\
\hline \multirow[t]{2}{*}{ Married status } & Single & $3.48 \pm 0.29$ & \multirow[t]{2}{*}{$0.001^{\mathrm{a}}$} \\
\hline & Married & $3.35 \pm 0.23$ & \\
\hline \multirow[t]{4}{*}{ Age range (year) } & $20-30$ & $3.47 \pm 0.29$ & \multirow[t]{4}{*}{$0.000^{\mathrm{b}}$} \\
\hline & $31-40$ & $3.34 \pm 0.18$ & \\
\hline & $41-50$ & $3.11 \pm 0.03$ & \\
\hline & $\geq 51$ & $3.41 \pm 0.26$ & \\
\hline \multirow[t]{3}{*}{ Education level } & Associate degree & $3.51 \pm 0.28$ & \multirow[t]{3}{*}{$0.000^{\mathrm{b}}$} \\
\hline & Bachelor's degree & $3.30 \pm 0.20$ & \\
\hline & Master's degree & $3.60 \pm 0.07$ & \\
\hline \multirow[t]{4}{*}{ Field of education } & Emergency medical services & $3.37 \pm 0.26$ & \multirow[t]{4}{*}{$0.000^{b}$} \\
\hline & Nurse & $3.46 \pm 0.27$ & \\
\hline & Anesthesia & $3.57 \pm 0.10$ & \\
\hline & Practical nurse & $3.66 \pm 0.11$ & \\
\hline \multirow[t]{4}{*}{ Work experience } & $5>$ & $3.44 \pm 0.32$ & \multirow[t]{4}{*}{$0.092^{b}$} \\
\hline & $6-10$ & $3.36 \pm 0.20$ & \\
\hline & $11-20$ & $3.36 \pm 0.17$ & \\
\hline & $21-30$ & $3.55 \pm 0.04$ & \\
\hline \multirow[t]{4}{*}{ Type of employment } & Formal & $3.44 \pm 0.26$ & \multirow[t]{4}{*}{$0.241^{b}$} \\
\hline & Contractual & $3.39 \pm 0.17$ & \\
\hline & Informal & $3.34 \pm 0.22$ & \\
\hline & Plan & $3.43 \pm 0.33$ & \\
\hline \multirow[t]{2}{*}{ Base of workplace } & Urban & $3.49 \pm 0.24$ & \multirow[t]{2}{*}{$0.000^{\mathrm{a}}$} \\
\hline & Road & $3.34 \pm 0.26$ & \\
\hline \multirow[t]{2}{*}{ Work hours per month } & $<150$ & $3.60 \pm 0.07$ & \multirow[t]{2}{*}{$0.000^{\mathrm{b}}$} \\
\hline & $200-150$ & $3.25 \pm 0.23$ & \\
\hline
\end{tabular}




\begin{tabular}{|c|c|c|c|}
\hline Variable & Groups & Mean \pm SD & P-Value \\
\hline & $250-200$ & $3.44 \pm 0.27$ & \\
\hline
\end{tabular}

Table 4

Relationship between occupational stress dimensions with work place of personnel of emergency medical center in Kermanshah Province

\begin{tabular}{|lllll|}
\hline P-Value & $\begin{array}{l}\text { Total individuals } \\
\mathbf{N}=\mathbf{2 0 0}\end{array}$ & $\begin{array}{l}\text { Road } \\
\mathbf{N}=\mathbf{4 5}\end{array}$ & $\begin{array}{l}\text { Urban } \\
\mathbf{N}=\mathbf{1 0 0}\end{array}$ & $\begin{array}{l}\text { Employees } \\
\text { Occupational stress dimensions }\end{array}$ \\
\hline 0.018 & $3.71 \pm 0.43$ & $3.65 \pm 0.45$ & $0.40 \pm 3.80$ & Demand \\
\hline 0.000 & $3.012 \pm 0.60$ & $2.95 \pm 0.59$ & $3.35 \pm 0.52$ & Control \\
\hline 0.43 & $2.87 \pm 0.68$ & $2.79 \pm 0.60$ & $2.99 \pm 0.76$ & Support of authorities \\
\hline 0.123 & $3.46 \pm 0.65$ & $3.40 \pm 0.78$ & $3.53 \pm 0.40$ & Support of colleagues \\
0.366 & $3.61 \pm 0.69$ & $3.65 \pm 0.66$ & $3.56 \pm 0.72$ & Relation \\
\hline 0.847 & $4.34 \pm 0.35$ & $4.35 \pm 0.39$ & $4.34 \pm 0.29$ & Role \\
\hline 0.038 & $2.72 \pm 0.86$ & $2.61 \pm 0.83$ & $2.87 \pm 0.89$ & Changes \\
\hline 0.000 & $3.41 \pm 0.26$ & $3.34 \pm 0.26$ & $3.49 \pm 0.24$ & Total occupational stress \\
\hline
\end{tabular}

\section{Discussion}

This study was conducted to investigate the occupational stress of the personnel of disaster and emergency medical management center 115 and the role of demographic variables in 2019. The results demonstrated that the highest and the lowest level of occupational stress was attributed to the "role" domain, followed by the "demand" and "changes" domain. In this regard, Hosseinzadeh et al. stated that the highest and the lowest occupational stress in emergency medical personnel were related to role and demand domain [25]. Sharifi et al. stated that demand dimension allocated the highest occupational stress and role dimension allocated the lowest occupational stress among emergency medical personnel [18]. Mei Lu et al. depicted that the subscale of problems related to time and workload based on the occupational stress questionnaire (which is consistent with the demand dimension of HSE questionnaire) were among the subscales that allocated the highest score among emergency medical nurses [21]. However, Mahdizadeh et al. concluded in their study that issues related to workload do not create much stress in personnel employed in 115 [26].

As it is clear, the strongest and the weakest factor of occupational stress in various studies is very diverse and even contradictory and in fact, it is influenced by the characteristics of the research sample. The role domain measures the "right understanding of individuals from the organization". In this study, it 
reveals that individuals do not have sufficient awareness of their duties and responsibilities, the goals and perspectives of the organization and the expectations that the work place have from them and therefore (especially according to the young research sample) training and justifications upon arrival and in-service by senior executives to clarify the problem and reduce occupational stress is helpful. Also, another main cause of occupational stress in this study was the demand dimension specifying overwork, long hours, lack of rest and rapid working, so senior executives can take measures such as providing sufficient work force, compulsion to use paid leave and so on can reduce occupational stress of employees. On the other hand, the dimension of changes is related to the "way of organizing and changing the forces of the organization", so it seems that in the present study, there is a good relationship between managers and employees regarding inter-organizational changes.

The results showed that younger people had experienced more occupational stress $(P=0.000)$. It should be noted that the sample population was young (more than half of the participants were in the age range of 20 to 30 years). Similarly, Moti et al. reported that as technicians' age increases to 40 to 45 years, their stress level is decreased [14]. It is natural that as the age and work experience increases, occupational stress decreases, in fact, increasing age to a certain level can have a protective role against stressors. D'Ettorre et al. stated that age had a significant relationship with occupational stress of nurses in emergency medical department [8].

However, Seyed Javadi et al. found contrast results in their study; as age increased, occupational stress increased in personnel employed in 115 [20]. Bardhan et al. considered age in relation with occupational stress, so that they announced that age over 40 is a risk factor for higher occupational stress among emergency medical nurses [27]. The researchers justified the results of their research so that by increasing age, the power of compatibility of individuals and coping with stressful work conditions is decreased, and it is natural that the occupational stress to be increased. In the present study, an increase was observed in stress in the age range of more than 50 years.

Another perspective observed in the present study demonstrate that single status account for more occupational stress than married status $(P=0.001)$. Similarly, Shareynia et al. reported that stress was higher among single nurses [4]. However, the study by Seyed Javadi et al. showed that there is no relationship between occupational stress of emergency medical technicians and marital status [20]. And, in contrast, Mahboubi et al. announced that married has more stress among emergency medical personnel [28]. The results of recent research justify the fact that single status attributes higher expectations from the family and the workplace which increases hours and workload and thus result in increased occupational stress.

Educational level had a significant relationship with the level of occupational stress experienced by individuals $(P=0.001)$. Only two percent of the participants in the study were postgraduate students who had experienced more occupational stress than others. Namdari et al. showed that as the level of education increased, the occupational stress of personnel employed in 115 increased and the tendency to continue service decreased which is in line with the present study [10]. By increasing education level as 
knowledge and skill increased and the quality of service is expected to improve, because expectations from people are higher and often are assumed to be more in difficult situations as specialized work is performed; therefore, it implies that occupational stress is increased as knowledge and skills improve. Moti et al. in their study concluded that technicians with a bachelor's degree had experienced more occupational stress compared to other people (with a diploma and associate degree), which is consistent with the present study, but ultimately there was no significant relationship between educational level and stressors [14]. People in stressful situations that require quick decision-making, regardless of their level of education, may not be able to act effectively and experience high stress.

There was a significant relationship between occupational stress and education degree $(P=0.000)$. In this study, the majority of participants $(80 \%)$ had emergency medical degree that had less stress compared to other fields of study (nursing, anesthesiology, and practical nurse). Similarly, Namdari et al. showed that occupational stress had a significant relationship with education field of emergency medical employees [10]. This issue can be justified so that emergency medical graduates have passed academic specialized training for providing service in pre-hospital conditions, thus they experience less occupational stress compared to other courses trained for hospital conditions. This issue shows the need to employ more relevant people in emergency medical centers as compared to general skill employees or ttain them in emergency situation. It seems natural that selecting people with a job-related degree will reduce workplace stress.

Furthermore, the results of this study reflected that people in urban bases generally had more occupational stress compared to people in road bases $(P=0.000)$. Similarly, Modi et al. and Namdari et al. stated that the stress in employees of urban base was higher than road base [10,14]. In the present study, the number of missions per day, the type of missions, and other factors associated with the type of base of work has not been investigated. Therefore, in case of further studies and confirmation of the relationship between these factors and occupational stress, it is suggested the workplace base periodically to be changed to modify and control stress and to be paid special attention to the personnel of bases with more workload. However, the study by Seyed Javadi et al. showed no relationship between stress level and type of base [20]. Leszczynski et al. stated that EMS employees experience varying degrees of stress in terms of work place. And in fact, there was a significant difference in the occupational stress of technicians working in emergency medical services and other services (earthy emergency medical services, emergency medical departments, etc.) and they had clearly experienced less stress [23]. Similar results were obtained in other medical groups, and Yuwanich et al. showed that nurses in the emergency medical department were more exposed to occupational stress compared to nurses in other sections due to their higher workload [15]. One general conclusion is that personnel experience different level of stress in different locations and departments.

By more investigation, it was specified that stress in employees of urban bases was more in the three dimensions of demand $(P=0.018)$, control $(P=0.000)$ and changes $(P=0.038)$. Therefore, it can be concluded that the main cause of more occupational stress is stress and workload (demand dimension), lack of control of person over the work being done (control dimension) and lack of adaptation to changes 
within the organization (change dimension) in urban bases. In this regard, Shareynia et al. revealed that there was a significant difference between the nurses in emergency and non-emergency medical department in terms of sub-scale of workload (due to high number of referrals) which increased their occupational stress [29]. Sharifi et al. stated that the dimensions of change, role, peer support, and responsible support had a significant relationship with the type of base of work [18].

The results showed that although the mean total score of occupational stress in people with experience less than 5 years and 21-30 years (both sides of the spectrum) was more than others, there was no significant relationship between work experience and occupational stress. Mati et al. reached quite similar results and stated that there was no relationship between work experience and occupational stress among emergency medical technicians, but in work experience of more than 20 years, the sum of scores of stressors was higher [14]. Yuwanich et al. [15] stated that low experience and work experience are related to occupational stress of nurses in emergency medical services and Bardhan et al. similarly indicated that work experience less than 10 years is a strong risk factor of higher occupational stress in nurses, which is somewhat consistent with the present study [27]. On the other hand, d'Ettorre et al. considered work experience related to occupational stress in burses of emergency medical services[8]. Another study also showed that by increasing work experience of personnel employed in 115, occupational stress also increased. The researchers described the finding that by increasing work experience, the overall duration of employees' presence at work placed increased and encountered stressors more [10]. Generally, it can be stated that occupational stress is present throughout the service of individuals, but it increases in amongst less experience and in the late stages of service.

Although it was expected occupational security to decrease the experience of stress but employees with more permanent employment (formal and contractual) had experienced high occupational stress, however, in the present study, a significant relationship was not observed between type of employment and the occupational stress. In this regard, some studies have shown that there is a significant relationship between employment status and occupational stress among technicians employed in 115 and nurses of emergency medical department $[10,28,29]$.

There was a significant relationship between working hours of personnel and their occupational stress, and unexpectedly, the results showed that people with the lowest working hours (less than 150 hours per month) experienced more occupational stress compared to others. This finding may be justified by the fact that being away from the workplace will increase the stress at the time of presence. However, the results of Shareinia et al. showed that there is a mild positive relationship between overtime and occupational stress; i.e the more overtime, the stress is increased in emergency medical nurses [4]. Another study showed that working hours per week was not related to occupational stress of employees employed in 115 [20].

\section{Conclusion}


Emergency medical personnel are at risk of high occupational stress due to the nature of their job.

Reducing the stress experienced by them in the workplace is critical and improves the quality of service provided to patients. Since manpower is the most important resource of any organization, senior managers should pay special attention to this issue and use the results of similar studies to develop strategies to reduce stress of employees.

\section{Abbreviations}

OS: Occupational Stress; EM:Emergency Medical; MC:Management Center; RD:Role of Demographic

\section{Declarations}

\section{Availability of data and materials}

Authors report that the data supporting their findings can be publicly shared.

\section{Ethics approval and consent to participate}

This study was drawn from a research project (No. IR. SBMU. PHNM. 1397.869) sponsored by the Deputy of Research and Technology at KUMS.

\section{Consent for publication}

Not applicable.

\section{Competing interests}

The authors declare that they have no competing interests.

\section{Funding}

There was no source of funding.

\section{Acknowledgments}

Our grateful thanks go to all participants in the present study.

\section{Authors'contributions}


All authors were responsible for study. JYL, RPK and AZ was responsible for the study Conceptualization and led the writing of the paper. PAG and VHG conducted the Literature review and assisted in writing the paper. AZ and JA conducted the Statistical analysis, assisted in interpreting the data and writing the paper. RT, JYL and MT assisted with interpretation of the results and drafting programmatic Implications. MRS, NK and AZ was responsible for data collection and coordination of the Study. AZ co-led the conceptualization, supervised all aspects of writing the Paper, and provided extensive comments on the manuscript. All the authors have read and approved the final manuscript.

\section{References}

1. Shams M, Rashidian A, Shojaeezadeh D, Majdzadeh SR, Montazeri A. Attitudes, self-reported and observational behaviors related to risky driving behaviors among taxi drivers in Tehran, Iran. Payesh (Health Monitor). 2010;9(4):403-16.

2. Torshizi L, Ahmadi F. Job stressors from clinical nurss perspective. Irain J Nurs. 2011;24(70):49-60.

3. Torshizi m, Saadatjoo SA. Job stress in the staff of a tire factory. J Birjand Unv Med Sci. 2012;19(2):200-7.

4. Shareinia H, Khuniki F, Bloochi Beydokhti T, Eydi zeynabad A, Hosseini M. Comparison between job stress among emergency department nurses with nurses of other departments. Q J Nurs Manag. 2017;6(3,4):48-55.

5. HazAVEhei S, Hosseini Z, Moeini B, Moghimbeigi A, Hamidi Y. Assessing stress level and stress management among Hamadan hospital nurses based on PRECEDE model. Ofogh-e-Danesh. J Gonabad Univ Med Sci. 2012;18(3):78-87.

6. Wang W, Kong AWM, Chair SY. Relationship between job stress level and coping strategies used by Hong Kong nurses working in an acute surgical unit. Applied Nurs Res. 2011;24(4):238-43.

7. Eltarhuni A. Job Stress Sources Among Doctors and Nurses Working in Emergency Departments in Public Hospitals. IOSR J Nurs Health Sci. 2016;5(6):84-8.

8. d'Ettorre G, Maselli C, Greco M, Pellicani V. Assessment and Management of Job Stress in Emergency Nurses: A Preliminary Study. Int J Emerg. 2015;18(4):1-3.

9. Abraham LJ, Thom O, Greenslade JH, Wallis M, Johnston AN, Carlström E, et al. Morale, stress and coping strategies of staff working in the emergency department: A comparison of two different-sized departments. Emerg Med Australasia. 2018;30(3):375-81.

10. Namdari M, Sharifi T, Tabatabee SS. The effect of job stress on the quality of life of emergency personnel. J Manag Med Inform School. 2014;2(1):37-27.

11. Franklin A, Liu Y, Li Z, Nguyen V, Johnson TR, Robinson D, et al. Opportunistic decision making and complexity in emergency care. J Biomed Inform. 2011;44(3):469-76.

12. Ebrahimi H, Navidian A, Ameri M, Sadeghi M. Burnout, dimensions and its related factors in the operational staff of medicine emergency. J Health Prom Manag. 2014;3(3):16-26. 
13. García-lzquierdo M, Ríos-Rísquez MI. The relationship between psychosocial job stress and burnout in emergency departments: An exploratory study. Nurs Outlook. 2012;60(5):322-9.

14. Motie Mr, Kalani M, Samadi A, Eshaghi H, Ghobadi P. Prevalence of job stressorsin male pre-hospital emergency technicians. J Fundament Mental Health. 2010;12(45):420-9.

15. Yuwanich N, Akhavan S, Nantsupawat W, Martin L. Experiences of occupational stress among emergency nurses at private hospitals in Bangkok, Thailand. Open J Nurs. 2017;7(6):657-70.

16. Patterson PD, Suffoletto BP, Kupas DF, Weaver MD, Hostler D. Sleep quality and fatigue among prehospital providers. Prehospital Emerg Care. 2010;14(2):187-93.

17. Berger AM, Hobbs BB. Impact of shift work on the health and safety of nurses and patients. Clin $\mathrm{J}$ Oncology Nurs. 2006;10(4):465-71.

18. Sharifi T, Namdari M, Hasheminejad N. The effect of job stress on the intention to stay as emergency personnel. J Sabzevar Univ Med Sci. 2016;23(1):133-42.

19. Dadashzadeh A, Rahmani A, Hasankhani H, Elmi S. Work Related Burden of Stress among Emergency Medical Service Personnel. Iran J Emerg Med. 2018;5:2.

20. Seyedjavadi M, Samadi N, Mohammadi R, Osmani A, Bakhtiari K, Seyedjavadi M. Assessment of Stress in Medical Emergency Staff in Ardabil Province. Qom Univ Med Sci J. 2014;7(6):41-5.

21. Executive HS. Tackling Stress: The Management Standard Approach. http://wwwhsegovuk/pubns/indg406pdf (1 January 2011, date last accessed). 2011.

22. Deniz T, Saygun M, Eroğlu O, Ülger H, Azapoğlu B. Effect of exposure to violence on the development of burnoutsyndrome in ambulance staff. Turkish J Med Sci. 2016;46(2):296-302.

23. Leszczyński P, Panczyk M, Podgórski M, Owczarek K, Gałązkowski R, Mikos M, et al. Determinants of occupational burnout among employees of the Emergency Medical Services in Poland. Ann Agricult Environ Med. 2019;26(1):114-9.

24. Azad ME, Gholami FM. Reliability and validity assessment for the HSE job stress questionnaire. J Behav Sci. 2011;4(4):291-97.

25. Hosseinzadeh M, Hosseinzadeh H, Razeghi N, Barzegar Z. The relationship between job satisfaction and job stress and its related factors among emergency medical services personnel of Mazandaran University of Medical Sciences in 2013. J Neyshabur Univ Med Sci. 2015;3(3):55-63.

26. Mahdizadeh M, Jaberi AA, Bonabi TN. Massage Therapy in Management of Occupational Stress in Emergency Medical Services Staffs: a Randomized Controlled Trial. Int J Therap Massage Bodywork. 2019;12(1):16-22.

27. Bardhan R, Heaton K, Davis M, Chen P, Dickinson DA, Lungu CT. A cross sectional study evaluating psychosocial job stress and health risk in emergency department nurses. Inte $\mathrm{J}$ Environ Res Public Health. 2019;16(18):3243-49.

28. Mahboubi M, Jalali A, Mohammadi M. Comparative assessment of relationship between sensation seeking with job stress in emergency medicine workers and non emergency medicine workers. Hospital J. 2013;12(3):132-8. 
29. Shareinia H, Khuniki F, Bloochi Beydokhti T. Comparison between job stress among emergency department nurses with nurses of other departments. Q J Nurs Manag. 2018;6(3):48-56. 